DEVELOPMENTAL ASPECTS OF DRUG TOXICITY

Baroukh M. Assael

Department of Pediatrics,University of Milano Medical

School, Milano, Italy

The inability of the neonate to metabolize drugs has been known for over 25 years (1). Together with poor renal function this is seen as a major source of risk of drug toxicity in early stages of development. In fact, several examples of drug toxicity (chloramphenicol, sulfonamides, digoxin etc.) in the neonate are associated with their excessive accumulation in body compartments.

However, the toxicity of several exogenous compounds (arugs, environmental pollutants) is thought to be due to their transformation into toxic intermediates in the body. Most foreign compounds undergo biotransformation such as oxidation, reduction, hydrolysis and conjugation. The fixst three mechanisms constitute phase I reactions during which intermediate metabolites are formed that are further converted to more polar compounds by phase II reactions. Both phase I and phase II reactions undergo developmental changes, but it may be hypothesized, and it has been shown in some cases, that an imbalance may occur between these two processes during maturation leading to an increased availability of potentially toxic, highly reactive intermediates (arene or alkene oxides) which may react with intracellular organelles and with DNA thus causing an elevated risk of mutagenesis. The $\mathrm{P}_{450}$ related monooxygenase, epoxide hydrolase and glutathione-s-transferase are the systems which have been best characterized during the development of various animal species $(2-4)$ and data are also available for human fetuses $(5,6)$.

Recent evidence has also shown that drug metabolizing enzymes are also present in the nuclear membrane. This system has potential importance since toxic or unstable metabolites formed in the nuclei may interact more easily with the genome than when formed in the microsomal fraction. Nuclear membrane enzymes have been found before birth in different species including man. They undergo developmental changes similar, but not identical, to those observed in the microsomal fraction. There are interspecies variations. The nuclear activity of styrene monooxygenase and epoxide hydrolase at the 15th day of gestation in the rat is as important as the microsomal one. In human fetuses at 15-17 weeks of gestation the microsomal metabolism is already predominant (6). This indicates the necessity for studies at earlier stages of pregnancy to better assess the role of nuclear drug metabolism in human developmental toxicology. In addition to the developmental aspects of the balance between toxifying and detoxifying enzymes the availability of endogenous substrates influences drug toxicity and teratogenicity. For example, gestational fluctuations in reduced glutathione have been found to be related to the teratogenicity of phenytoin (7). In addition to its biological interest this observation may provide a rationale for studies on the prevention of fetal toxicity.

References:

1. Assael BM 1982 Pharmacokinetics and drug distribution during postnatal development. Pharmac Ther $18,159-197$

2. Atlas SA, Boobis AR, Felton JS, Thorgeirsson SS, Nebert DW 1977 ontogenetic expression of polycyclic aromatic compound-inducible monooxygenase activities and forms of cytochrome $\mathrm{P}_{450}$ in the rabbit. J Biol Chem 252, 4712-4721
3. Oesch F 1979 Epoxide hydratase. In: Bridges JW, Chasseaud LF (Eds), Progress in Drug Metabolism. Chichester, England, John Wiley, vol. 3, 253-301

4. Mukhtar H, Philpot RM, Bend JR 1978 The postnatal development of microsomal epoxide hydratase, cytosolic glutathione-s-transferase and mitochondrial and microsomal cytochrome $\mathrm{P}_{450}$ in adrenals and ovaries of female rats. Drug Metab Disposit $6,577-583$

5. Pacifici GM, Norlin A, Rane A 1981 Glutathione S transferase in human fetal liver. Biochem Pharma$\operatorname{col} 30,3367-3371$

6. Romano M, Tursi F, Assael BM, Buscaglia M, Dell' Agnola CA, Salmona M 1983 Nuclear drug metabolism: its ontogeny in the rat and its presence in human fetal life. In: MacLeod SM, Okey AB, Spielberg SP (Eds), Developmental Pharmacology, Alan Liss Inc. New York 395-400

7. Wells PG 1983 Physiological and environmental determinants of phenytoin toxicity: relation to glutathion homeostasis and potentiation by acetaminophen. In: MacLeod SM, Okey AB, Spielberg SP (Eds), Developmental Pharmacology, Alan Liss Inc, New York, 367-371

\section{SELENIUM REQUIREMENT IN CHILDREN}

Ingrid Lombeck

University Children's Hospital, Düsseldorf, FRG

Selenium - first known as a naturally occurring toxicant - belongs to the essential trace elements. Biological effects occur at selenium concentrations mainly in the range of $0.05-5.0 \mu \mathrm{g} / \mathrm{g}$ of diet or tissue. Besides some seleno-enzymes and specific selenoproteins in bacterial and animal tissues glutathione peroxidase is the only seleno-enzyme proven to occur in humans. Its activity is dependent on the selenium state. This enzyme protects membranes against oxidative damage. The requirement for optimum health and growth is far from being known and its role in human deficiency diseases is complicated. During childhood selenium state shows a marked age relationship. At birth the selenium content of the liver is higher than in adults suggesting the accretion of selenium stores in gestation $(1,2,8)$. Hair selenium shows a similar phenomenon, in neonates the selenium content is $200 \%$ of the mother's selenium (790 $\mathrm{ng} / \mathrm{g}$ versus $400 \mathrm{ng} / \mathrm{g}$ ) (9). In contrast the plasma selenium concentration is low reflecting probably a reduced selenium placental transport during the last days of pregnancy. The erythrocyte or whole blood value may still be normal or low. During the first months of life the selenium content of serum, whole blood decreases. This decrease is steeper in premature than in mature babies, more pronounced in formula-fed infants than in breast-fed infants and most profound in parenterally-fed infants. Thus reflecting the low selenium-intake. Whereas the selenium intake during the first trimenon is between 10 and $22 \mu \mathrm{g}$ with mothers milk in socalled selenium adequate areas it is 20 to $67 \%$ lower in formula-fed infants.

During the second half year of life the selenium intake and consequently the selenium state is rising. This increase is produced in western countries mainly by the addition of cereals to the milk and to a lower degree by animal proteins with a higher selenium content f.e. egg yolk. In West Germany at the end of the first year the selenium intake amounts to $34 \mu \mathrm{g}$ cf which $44 \%$ derive from cereals. The 
selenium content of cereals exhibits greater regional variations than that of dairy or meat products. Thus, the intake of young children is markedly influenced by the origin of their cereals. Processing may also decrease the selenium content of food-stuffs. Commer cially available meals contain less selenium than home-made ones ( $30 \mathrm{ng} / \mathrm{g}$ versus $50 \mathrm{ng} / \mathrm{g}$ ). Data about the gradual increase of the selenium intake during later childhood are scanty. In healthy adults the selenium intake ranges from about $20 \mu \mathrm{g} /$ day in New Zealand to $326 \mu \mathrm{g} /$ day in Venezuela, or from $11 \mu \mathrm{g} / \mathrm{day}$ in selenium deficient areas in China to $4990 \mu \mathrm{g} /$ day in seleniferous areas.

Because of rapid growth children are more prone to selenium-deficiency states than adults. Groups at risk are besides formula-fed infants, children from selenium-poor areas (New Zealand, Finland and China) patients on parenteral nutrition or on semisynthetic diets. Reduced selenium states were first observed in patients with kwashiorkor. Selenium supplementation was reported to ameliorate the clinical condition of those patients from Guatemala. Selenium supplementation was also tried in patients with muscular dystrophy of Duchenne type.

Recent reports from China have shown a causal relationship between Keshan disease and selenium deficien cy (3). This endemic cardiomyopathy occurred mainly in children and women of child bearing age in a long montaneous belt reaching from northeast to southwest of China. First low hair selenium values $(<120 \mathrm{ng} / \mathrm{g})$ were detected in children from affected areas. The selenium content of blood $(21+10 \mathrm{ng} / \mathrm{ml}$ was as well reduced as the erythrocyte glutathione peroxidase activity. This low selenium state derived from the low selenium intake by grains grown on soils with little available selenium. Selenium supplementation lead to a complete prevention of the disease. In two adults and in 12 yr old child on a self-selected selenium-poor diet a cardiomyopathy was published and muscle pain, tenderness and fingernail-bed anomalies in an $8 \mathrm{yr}$ old boy on total parenteral nutrition (6) In China, in Keshan disease but also in Kaschin-Beck disease, selenium deficiency seems to play an important part in the etiology or pathogenesis (7). Kasschin-Beck disease is an osteoarthropathy with a disturbance of the enchondral ossification and deformity of affected joints. The low selenium content in cereals from Kaschin-Beck disease-affected areas was occasionally discovered as rats fed with these cereals suffered from typical signs of selenium deficiency, liver necrosis and white muscle disease. It is unclear whether Keshan disease and Kaschin-Beck disease are purely selenium deficiency diseases or whether other nutritional environmental and infectious factors contribute to the pathogenesis.

Selenium requirement may be different under different nutritional environmental, genetic and health conditions. Dietetically treated patients with PKU do not suffer from cardiomyopathy although their selenium states are equally low as in Chinese children from Keshan-affected areas. The food composition may cause this difference. Interactions between selenium and proteins or methionine, vitamin E, arsenic, silver, mercury, polyunsaturated fatty acids are reported in animals. The nature of selenium compounds present in natural foods and their bio-availability is far from being known. In adults contradictory results about selenite-selenium, selenomethionine, Se-wheat, Se-yeast, fish-Se were published. In children with reduced selenium state on parenteral nutrition or semisynthetic diets selenium supplementation with selenite-Se $(3 \mu \mathrm{g} / \mathrm{kg} / \mathrm{d}$, parenterally) or se-yeast (135 $\mu \mathrm{g} / \mathrm{m}^{2} / \mathrm{d}$, orally) was shown to be very effective. The selenium content and glutathion peroxidase activity of plasma increased within days and also the platelet glutathione peroxidase activity. Platelets belong to the tissues with high selenium content and corresponding glutathionine peroxidase activity. Erythrocyte glutathionine peroxidase activity only shows a change after long-term supplementation. Long-term changes of selenium supply can be also monitored by head hair analysis. A selenium depletion quickly occurs in infants during rapid growth. In older children or repleted patients a reduced selenium intake needs months to show off in glutathione peroxidase activities of plasma, platelets or erythrocytes. At the moment we do not know the safe and adequate range of selenium intake in children. Do the formula-fed infants with low blood and hair selenium values already suffer from a manifest or marginal selenium deficiency state, which may induce long-term effects on their health? At which level selenium intoxification may occur, either acute or chronic or by diminishing the bioavailability of other essential food stuffs?

Acute selenium poisoning with unknown amounts of selenious acid or selenite was reported in three children, of whom one died 3 hours later. All three suffered besides the garlic odour from uncharacteristic symptoms, like hypersalivation, vomiting, diarrhoea, restlessness, arrhythmia. Plasma selenium was 20 times normal and urine selenium 100 times normal (5).

Selenium has a rather narrow therapeutic range. Supplementations should be performed only if necessary and carefully monitored to avoid intoxications or imbalances with other nutritional components.

References:

1) Bayliss PA et al 1985 Biol Trace Elem Res 7, 53

2) Casey E et al 1982 Arch Environ Health 37: 133

3) Chen $x$ et al 1980 Biol Trace Elem Res 2: 91

4) Collip PJ, Chen Sy 1981 New Engl J Med 304, 1305

5) Lombeck I et al (in press) 1986 Eur J Ped

6) Kien CI, Ganther H.E $1983 \mathrm{Am} \mathrm{J} \mathrm{Clin} \mathrm{Nutx} \mathrm{37:319}$

7) Dongxu M, Peking, 3.5.1984, III. Int. SIMP Se.

8) Westermarck T 1977 Acta Pharmacol Toxicol 41, 121

9) Widdra S, Lombeck I: unpublished results

\section{PRENATAL NEUROLOGY}

Heinz F.R. Prechtl

Department of Developmental Neurology, University of Groningen, Groningen, The Netherlands

The relationship between obstetrical complications and neurological sequelae has frequently been investigated by correlating perinatal data with neurological follow-up data.

There is always a considerable time lag between these two data sources. It is now possible to assess the condition of the fetal nervous system during the acute or chronic phase of obstetrical complications without such delay through ultrasound observations of the fetus.

Fetal movement patterns are from their first onset (8-14 weeks p.m. age) distinct and coordinated and resemble patterns known from the newborn infant. They are endogenously generated and their incidence of occurrence follows a developmental course during pregnancy, which is specific for each individual movement pattern. They first appear following a characteristic time table (1). Quantitative assessment of the different movement patterns reveals an age specific motor repertoire in all longitudinally observed fetuses (2). 